\title{
Epidemic characterization and molecular genotyping of Shigella flexneri isolated from calves with diarrhea in Northwest China
}

\author{
Zhen Zhu $^{\dagger}$, Mingze Cao ${ }^{\dagger}$, Xuzheng Zhou, Bing Li and Jiyu Zhang ${ }^{*}$
}

\begin{abstract}
Background: The widespread presence of antibiotics resistance genes in pathogenic bacteria can cause enormous problems. Food animals are one of the main reservoirs of intestinal pathogens that pose a potential risk to human. Analyzing the epidemiological characteristics and resistance patterns of Shigella flexneri in calves is necessary for animal and human health.

Methods and results: A total of 54 Shigella flexneri isolates, including six serotypes (1a, 2a, 2b, 4a, 6 and Xv), were collected from 837 fecal samples obtained from 2014 to 2016. We performed pulsed-field gel electrophoresis (PFGE) and applied the restriction enzyme Notl to analyze the genetic relatedness among the 54 isolates and to categorize them into 31 reproducible and unique PFGE patterns. According to the results of antimicrobial susceptibility tests, all 26 Shigella flexneri 2a serotypes were resistant to cephalosporin and/or fluoroquinolones. The genes bla $a_{T E M-1}, b_{1} a_{O X A-1}$, and bla ${ }_{C T X-M-14}$ were detected in 19 cephalosporin-resistant $S$. flexneri $2 \mathrm{a}$ isolates. Among 14 fluoroquinolone-resistant isolates, the $a a c\left(6^{\prime}\right)-1 b$-cr gene was largely present in each strain, followed by qnrS (5). Only one ciprofloxacin-resistant isolate harbored the gepA gene. Sequencing the quinolone resistance determining regions (QRDRs) of the fluoroquinolone-resistant isolates revealed two point mutations in gyrA ( $883 \mathrm{~L}, \mathrm{D} 87 \mathrm{~N} / \mathrm{Y})$ and a single point mutation in parC (S80l). Interestingly, two gyrA (D87N/Y) strains were resistant to ciprofloxacin.
\end{abstract}

Conclusions: The current study enhances our knowledge of Shigella in cattle, although continual surveillance is necessary for the control of shigellosis. The high level of cephalosporin and/or fluoroquinolone resistance in Shigella warns us of a potential risk to human and animal health.

Keywords: Shigella flexneri, Antimicrobial susceptibility, Resistant

\section{Background}

The majority of Enterobactericeae family bacteria, including Salmonella, E. coli and Shigella spp., the major etiological agent of diarrheal disease, are a global public health burden, particularly in low-income countries [1-3]. Shigella is phylogenetically distinct from several independent $E$. coli strains and has evolved through convergent evolution [4]. The genus Shigella consists of four subgroups differentiated according to their biochemical and serological properties: A (S. dysenteriae), B (S. flexneri), C (S. boydii), and D ( $S$.

\footnotetext{
*Correspondence: infzjy@sina.com

${ }^{\dagger}$ Equal contributors

Key Laboratory of New Animal Drug Project of Gansu Province, Key Laboratory of Veterinary Pharmaceutical Development of Ministry of Agriculture, Lanzhou Institute of Husbandry and Pharmaceutical Sciences of CAAS, Jiangouyan, Qilihe District, Lanzhou, People's Republic of China
}

sonnei). All four species of Shigella cause shigellosis, but $S$. flexneri is the predominant subgroup found in developing countries, whereas $S$. sonnei is found in industrialized countries [5]. The first Shigella species identified was $S$. dysenteriae, followed by S. flexneri at the end of the 19th century. Shigellosis became a notorious and widespread epidemic during World War 1 with the transmission of $S$. flexneri strain NCTC1, a 2a lineage [6, 7]. Based on the differing structural characteristics of the antigenic determinants of the $\mathrm{O}$ antigen, $S$. flexneri is divided into no fewer than 20 serotypes: 1a, 1b, 1c, 1d, 2a, 2b, 2v, 3a, 3b, 4a, 4av, $4 \mathrm{~b}, 4 \mathrm{c}, 5 \mathrm{a}, 5 \mathrm{~b}, \mathrm{X}, \mathrm{Xv}, \mathrm{Y}, \mathrm{Yv}, 6$, and 7b $[8,9]$.

Given that shigellosis is a global public health burden, previous studies have focused on the human gastrointestinal pathogens but have ignored animal groups. Shigella spp. infect and also cause corresponding clinical 
symptoms in monkeys, cows, pigs, chickens and other animals [10-13]. Indeed, animals that live in environments characterized by poor sanitary hygiene, restricted access to clean drinking water and long-term exposure to contaminated food are prone to dysentery [14, 15]. Many antibiotics are used to control disease and promote growth during the breeding process, leading to the widespread dissemination of antibiotic resistance genes (ARGs). The spread of drug resistance among pathogenic bacteria in humans and animals may be disastrous.

The present study investigated the Shigella epidemic in cows in the northwest region of China. S. flexneri 2a was first isolated from a yak with diarrhea in Tibet in 2014. In this study, we used pulsed-field gel electrophoresis (PFGE) to analyze the relationships among $S$. flexneri isolates and tested for antimicrobial susceptibility patterns. Our results will help prevent diarrhea in calves and will assist in the selection of effective antibiotics against Shigella.

\section{Methods}

\section{Bacterial isolation and identification}

Fresh stool samples were isolated from 2014 to 2016 in Northwest China (Gansun, Shanxi, Qinghai, Xinjiang and Tibet) from calves (3 to 20 days) with diarrhea. Samples were stored in transport medium, cultured directly on Salmonella-Shigella (SS) agar and incubated at $37^{\circ} \mathrm{C}$ for $24 \mathrm{~h}$ to select for Shigella. Resultant colonies (colorless, semitransparent, smooth, and moist circular) [16] were picked and grown at $37{ }^{\circ} \mathrm{C}$ for $24 \mathrm{~h}$ on MacConkey (MAC) Agar to verify identity. Colonies were selected and cultured in brain heart infusion broth at $37{ }^{\circ} \mathrm{C}$ for $5 \mathrm{~h}$ with shaking at $250 \mathrm{rpm}$. All isolates were confirmed using API20E test strips (bioMerieux Vitek, Marcy-l' Etoile, France) according to the manufacturer's recommendations. Shigella was serotyped using a commercially available kit (Denka Seiken, Tokyo, Japan) and confirmed by PCR [17].

\section{Antimicrobial susceptibility testing}

The antimicrobial susceptibility of $S$. flexneri isolates was determined via the Kirby-Bauer disc-diffusion method in accordance with the guidelines of the Clinical and Laboratory Standards Institute (CLSI) [18].

The antibiotic discs (OXOID, UK) included penicillin G (P, $10 \mu \mathrm{g}$ ), ampicillin (AMP, $10 \mu \mathrm{g}$ ), amoxicillin/clavulanic acid (AMC, $30 \mu \mathrm{g}$ ), cephalothin (KF, $30 \mu \mathrm{g}$ ), cephazolin $(\mathrm{KZ}, 30 \mu \mathrm{g})$, cefamandole (MA, $30 \mu \mathrm{g})$, cefoxitin (FOX, $30 \mu \mathrm{g})$, ceftriaxone (CRO, $30 \mu \mathrm{g})$, cefotaxime (CTX, $30 \mu \mathrm{g}$ ), cefoperazone (CFP, $75 \mu \mathrm{g}$ ), cefepime (FEP, $30 \mu \mathrm{g}$ ), meropenem (MEM, $10 \mu \mathrm{g})$, imipenem (IPM, $10 \mu \mathrm{g})$, norfloxacin (NOR, $10 \mu \mathrm{g}$ ), enrofloxacin (ENR, $5 \mu \mathrm{g}$ ), levofloxacin (LEV, $5 \mu \mathrm{g}$ ), ciprofloxacin (CIP, $5 \mu \mathrm{g}$ ), erythromycin $(\mathrm{E}, 15 \mu \mathrm{g})$, chloramphenicol $(\mathrm{C}, 30 \mu \mathrm{g})$, tetracycline (TE,
$30 \mu \mathrm{g})$, streptomycin $(\mathrm{S}, 10 \mu \mathrm{g})$, gentamicin $(\mathrm{CN}, 10 \mu \mathrm{g})$, and amikacin (AK, $30 \mu \mathrm{g})$. E. coli strain ATCC25922 was used as a quality control strain in each test batch.

\section{PCR amplification of ARGs}

We performed PCR assays that targeted 24 different ARGs using the primers described in Table 1. To determine the underlying resistance mechanism of $\beta$-lactam antibiotics, we amplified extended-spectrum $\beta$-lactamase (ESBL) genes, specifically bla $a_{C T X-M}, b l a_{S H V}, b l a_{T E M}$, and $b l a_{O X A}$, as well as $a m p C$ genes, specifically $b l a_{M O X}, b l a_{F O X}$, $b l a_{D H A}, b l a_{C I T}, b l a_{A C C}$, and $b l a_{M I R}$ [19-21]. Plasmidmediated quinolone resistance (PMQR) determinant genes, including $q n r A, q n r B, q n r D, q n r S$, qepA and $a a c\left(6^{\prime}\right)-\mathrm{Ib}-\mathrm{cr}$ and four quinolone resistance determining region (QRDR) genes as well as DNA gyrase $(\operatorname{gyr} A, \operatorname{gyr} B)$ and topoisomerase IV (parC,parE) were amplified to determine the underlying mechanism of quinolone resistance [16, 21-23]. The PCR fragments were sequenced after purification and compared to sequences in GenBank.

\section{PFGE}

Genotypes and transmission patterns were determined by performing PFGE according to the method described in a previous study [19]. S. flexneri isolates were digested with the restriction enzyme NotI (TaKaRa, Japan) at $37{ }^{\circ} \mathrm{C}$ for $3 \mathrm{~h}$ to generate a DNA fingerprinting profile. Salmonella enterica serotype Braenderup strain H9812 was digested with $X b a \mathrm{I}$ (TaKaRa, Japan) and used as a molecular size standard. Electrophoresis was performed on the CHEF Mapper XA system (Bio-Rad) with a $1 \%$ agarose SeaKem Gold gel (Lonza, USA). Electrophoretic parameters were determined by performing multiple screening runs and included switching times of 2.16 to $54.17 \mathrm{~s}$, a voltage of 6 $\mathrm{v} / \mathrm{cm}$, a $120^{\circ}$ angle and a run time of $21 \mathrm{~h}$. PFGE images were obtained using a Universal Hood II (Bio-RAD, USA) and analyzed using BioNumerics software version 7.1 (Applied Maths, Sint-Martens-Latem, Belgium). A clustering tree that indicated relative genetic similarity was constructed using UPGMA (Unweighted Pair Group Method with Arithmetic Mean) and the Dice-predicted similarity value with a $1.0 \%$ pattern optimization and $1.5 \%$ band position tolerance.

\section{Results}

\section{Bacterial isolation and identification}

During our epidemiological survey of Shigella, we collected 873 fecal samples from calves with diarrhea and obtained 54 S. flexneri isolates from five provinces in northwest China from 2014 to 2016. Isolate information is shown in detail in Table 2. Among the 54 S. flexneri isolates, there were six serotypes: five $(9.26 \%)$ isolates were 1a, twenty-six $(48.15 \%)$ isolates were $2 \mathrm{a}$, four (7.41\%) isolates were $2 \mathrm{~b}$, six $(11.11 \%)$ isolates were $4 \mathrm{a}$, 
Table 1 Primers for the detection of antibiotic resistance genes

\begin{tabular}{|c|c|c|c|}
\hline Target & Primer sequence ( $5^{\prime}$ to $\left.3^{\prime}\right)$ & Amplicon size (bp) & Reference \\
\hline \multicolumn{4}{|l|}{$\beta$-lactamase } \\
\hline \multirow[t]{2}{*}{ bla $a_{C T X-M-1}$} & F: GGTTAAAAAATCACTGCGTC & 873 & Cui et al., 2015 [16] \\
\hline & R: TTACAAACCGTCGGTGACGA & & \\
\hline \multirow[t]{2}{*}{$b / a_{C T X-M-2}$} & F: CGACGCTACCCCTGCTATT & 552 & Zong et al., 2008 [17] \\
\hline & R: CCAGCGTCAGATTTTTCAGG & & \\
\hline \multirow[t]{2}{*}{$b l a_{C T X-M-8}$} & F: TCGCGTTAAGCGGATGATGC & 689 & Zong et al., 2008 [17] \\
\hline & R: AACCCACGATGTGGGTAGC & & \\
\hline \multirow[t]{2}{*}{$b l a_{C T X-M-9}$} & F: AGAGTGCAACGGATGATG & 868 & Cui et al., 2015 [16] \\
\hline & R: CCAGTTACAGCCCTTCGG & & \\
\hline \multirow[t]{2}{*}{ bla $a_{C T X-M-25}$} & F: TTGTTGAGTCAGCGGGTTGA & 497 & Liu et al., 2015 [18] \\
\hline & R: GCGCGACCTTCCGGCCAAAT & & \\
\hline \multirow[t]{2}{*}{$b^{\prime} a_{S H V}$} & F: CGCCGGGTTATTCTTATTTGTCGC & 1015 & Zong et al., 2008 [17] \\
\hline & R: TCTTTCCGATGCCGCCGCCAGTCA & & \\
\hline \multirow[t]{2}{*}{$b l a_{T E M}$} & F: ATGAGTATTCAACTITCCG & 876 & This study \\
\hline & R: CCAATGCTTAATCAGTGAG & & \\
\hline \multirow[t]{2}{*}{$b l a_{O X A}$} & F: ATTAAGCCCTITACCAAACCA & 890 & Cui et al., 2015 [16] \\
\hline & R: AAGGGTTGGGCGATTTTGCCA & & \\
\hline \multirow[t]{2}{*}{ bla } & F: GCTGCTCAAGGAGCACAGGAT & 520 & Cui et al., 2015 [16] \\
\hline & R: CACATTGACATAGGTGTGGTGC & & \\
\hline \multirow[t]{2}{*}{ bla FOX } & F: AACATGGGGTATCAGGGAGATG & 190 & Cui et al., 2015 [16] \\
\hline & R: CAAAGCGCGTAACCGGATTGG & & \\
\hline \multirow[t]{2}{*}{$b l a_{D H A}$} & F: AACTTTCACAGGTGTGCTGGGT & 405 & Cui et al., 2015 [16] \\
\hline & R: CCGTACGCATACTGGCTITGC & & \\
\hline \multirow[t]{2}{*}{$b l a_{C I T}$} & F: TGGCCAGAACTGACAGGCAAA & 462 & Cui et al., 2015 [16] \\
\hline & R: TITCTCCTGAACGTGGCTGGC & & \\
\hline \multirow[t]{2}{*}{$b l a_{A C C}$} & F: AACAGCCTCAGCAGCCGGTTA & 346 & Cui et al., 2015 [16] \\
\hline & R: TTCGCCGCAATCATCCCTAGC & & \\
\hline \multirow[t]{2}{*}{ blamir } & F: TCGGTAAAGCCGATGTTGCGG & 302 & Cui et al., 2015 [16] \\
\hline & R: CTTCCACTGCGGCTGCCAGTT & & \\
\hline \multicolumn{4}{|l|}{ PMQRs } \\
\hline \multirow[t]{2}{*}{ qnrA } & F: ATTTCTCACGCCAGGATTTG & 516 & Colobatiu et al.,2015 [19] \\
\hline & R: GATCGGCAAAGGTTAGGTCA & & \\
\hline \multirow[t]{2}{*}{$q n r B$} & F: GATCGTGAAAGCCAGAAAGG & 476 & Colobatiu et al.,2015 [19] \\
\hline & R: ACGATGCCTGGTAGTTGTCC & & \\
\hline \multirow[t]{2}{*}{ anrD } & F: CGAGATCAATTACGGGGAATA & 656 & Cui et al.,2015 [13] \\
\hline & R: AACAAGCTGAAGCGCCTG & & \\
\hline \multirow[t]{2}{*}{ anrs } & F: ACGACATTCGTCAACTGCAA & 417 & Colobatiu et al.,2015 [19] \\
\hline & R: TAAATTGGCACCCTGTAGGC & & \\
\hline \multirow[t]{2}{*}{$a a c\left(6^{\prime}\right)-1 b-c r$} & F: CCCGCTTTCTCGTAGCA & 544 & Colobatiu et al.,2015 [19] \\
\hline & R: TTAGGCATCACTGCGTCTTC & & \\
\hline \multirow[t]{2}{*}{ qерA } & F: CGTGTTGCTGGAGTTCTTC & 403 & Colobatiu et al.,2015 [19] \\
\hline & R: CTGCAGGTACTGCGTCATG & & \\
\hline \multicolumn{4}{|l|}{ QRDR } \\
\hline gyrA & F: TACACCGGTCAACATTGAGG & 648 & Hu et al.,2007 [20] \\
\hline
\end{tabular}


Table 1 Primers for the detection of antibiotic resistance genes (Continued)

\begin{tabular}{|c|c|c|c|}
\hline & R: TTAATGATTGCCGCCGTCGG & & \\
\hline \multirow[t]{2}{*}{ gyr $B$} & F: TGAAATGACCCGCCGTAAAGG & 309 & Hu et al.,2007 [20] \\
\hline & R: GCTGTGATAACGCAGTTGTCCGGG & & \\
\hline \multirow[t]{2}{*}{ parC } & F: GTACGTGATCATGGACCGTG & 531 & Hu et al.,2007 [20] \\
\hline & R: TTCGGCTGGTCGATTAATGC & & \\
\hline \multirow[t]{2}{*}{ parE } & F: ATGCGTGCGGCTAAAAAAGTG & 290 & Hu et al.,2007 [20] \\
\hline & R: TCGTCGCTGTCAGGATCGATAC & & \\
\hline
\end{tabular}

eight (14.81\%) isolates were 6, and five (9.26\%) isolates were Xv (Fig. 1). Our surveillance of the Gansu isolates identified all of the serotypes, except 4a. All 4a serotypes were isolated from Shanxi, while all Xv and 1a serotypes were from Gansu. Additionally, serotype 2a was widely isolated from each province, with the exception of Xinjiang, and serotype 6 was found only in yaks. Interestingly, Shigella was primarily isolated in the first quarter and fourth quarter, accounting for 54\% (29/54) and $30 \%$ (16/54), respectively (Fig. 2).

\section{Antimicrobial susceptibility testing}

The 54 S. flexneri isolates were examined for susceptibility to 23 antibiotics. More than $50 \%$ of isolates were resistant to 8 antibiotics. Among them, resistance to $\mathrm{P}$ (54/54, 100\%), AMP $(51 / 54,94.44 \%)$ and TE $(49 / 54,90.74)$ was most common, followed by $\mathrm{E}(46 / 54,85.19 \%)$, S (38/54, $70.37 \%), \mathrm{KZ}(34 / 54,62.96 \%), \mathrm{KF}(29 / 54,53.70 \%)$ and $\mathrm{CN}$ $(29 / 54,53.70 \%)$. None of the isolates were resistant to IMP, MEM and the fourth-generation cephalosporin FEP. In addition, although a certain number of isolates were resistant to second- and third-generation cephalosporins (MA, FOX, CRO, CTX and CFP) and fluoroquinolones (CIP, NOR, ENR and LEV), these comprised no more than $30 \%$ of the total number of isolates, and the resistance rate was lower than those of other antibiotics (Table 3, Fig. 3).

Remarkably, all 26 S. flexneri 2a isolates demonstrated varying degrees of resistance to cephalosporins and/or fluoroquinolones and exhibited multidrug resistance (MDR). The S. flexneri 2a isolates were resistant to 14 diverse cephalosporins/fluoroquinolones. Among them, $73.06 \%(19 / 26)$ of isolates were resistant to cephalosporin, $53.85 \%(14 / 26)$ of isolates were resistant to fluoroquinolones, and $26.92 \%(7 / 26)$ of isolates were resistant to both cephalosporin and fluoroquinolones. Furthermore, isolate GBSF1512433 was resistant to all cephalosporins (with the exception of FEP) and fluoroquinolones (with the exception of CIP). Compared with the S. flexneri 2 a isolates collected from beef calves, the 4 yak isolates were sensitive to most cephalosporins and fluoroquinolones but resistant to $\mathrm{KF}, \mathrm{KZ}$ and MA (Table 4).

\section{ARGs analysis of cephalosporin- and/or fluoroquinolone- resistant $S$. flexneri $2 \mathrm{a}$ isolates}

In this study, only three $\beta$-lactamase gene types (bla $a_{O X A-1}$, $b l a_{T E M-1}$ and $\left.b l a_{C T X-M-14}\right)$ were identified among the 19 cephalosporin-resistant $S$. flexneri 2a isolates (Table 5). All isolates harbored $b l a_{T E M-1}$ type ARGs (100\%), 15 isolates harbored bla $a_{O X A-1}(15 / 19,78.95 \%)$, and 14 harbored bla $_{C T X-M-14}(14 / 19,73.68 \%)$. In total, 63.16\% (12/19) of isolates harbored three $\beta$-lactamase gene types. All $S$. flexneri $2 \mathrm{a}$ isolates from yaks were negative for bla ${ }_{C T X-M}$ type ARGs.

Both PMQR genes and SNPs in QRDRs were identified for 14 quinolone-resistant isolates (Table 6). According to the PCR results, all quinolone-resistant isolates were positive for $a a c\left(6^{\prime}\right)-I b-c r$ but negative for $q e p A$, except strain GBSF1602098. Only five $(5 / 14,35.71 \%)$ strains isolated from Gansu harbored $q n r S$, and no isolate harbored all three ARGs simultaneously. The point mutations in the QRDR genes play important roles in determining quinolone and/or fluoroquinolone resistance [24]. In the present study, we successfully amplified all four QRDR genes and compared them to reference sequences. We found two point mutations in gyrA and one point mutation each in $g y r A$ and parC (Table 6). All quinoloneresistant strains carried mutations that altered the amino acid sequences of gyrA (S83 L) and parC (S80I). In addition, each strain carried the mutation $87(\mathrm{D} \rightarrow \mathrm{N}$ or Y) in $g y r A$, with the exception of GBSF1510390. Interestingly, GBSF1505314 and GBSF1602098 harbored the gyrA D87Y mutation, which confers resistance to ciprofloxacin.

\section{PFGE pattern analysis}

PFGE was performed to determine the genetic relatedness among the isolates and to study the molecular epidemiology in specific geographical regions [25]. The PFGE patterns of the 54 NotI-digested S. flexneri isolates were heterogeneous, and multiple PFGE patterns were present among the strains. Thus, diverse factors such as geography and environment may affect PFGE patterns. At an $80 \%$ similarity level, S. flexneri isolates generated 31 reproducible and unique PFGE patterns, including 11 common types (CT) and 20 single types (ST) (Fig. 3). 
Table 2 Strain information of S. flexneri isolates from diarrheal calves, 2014 to 2016

\begin{tabular}{|c|c|c|c|c|}
\hline Strain name & Serotype & Isolation year & Origin & Province \\
\hline TYSF1412001 & $2 a$ & 2014 & Yak & Tibet \\
\hline GBSF1412056 & $2 a$ & 2014 & Beef cattle & Gansu \\
\hline GBSF1501026 & $2 a$ & 2015 & Beef cattle & Gansu \\
\hline GBSF1501071 & $X_{v}$ & 2015 & Beef cattle & Gansu \\
\hline GYSF1501076 & 6 & 2015 & Yak & Gansu \\
\hline QYSF1501088 & 6 & 2015 & Yak & Qinghai \\
\hline XBSF1501093 & $2 b$ & 2015 & Beef cattle & Xinjiang \\
\hline GBSF1501105 & $2 a$ & 2015 & Beef cattle & Gansu \\
\hline SBSF1501123 & $4 a$ & 2015 & Beef cattle & Shanxi \\
\hline QYSF1502130 & 6 & 2015 & Yak & Qinghai \\
\hline GBSF1502176 & $2 a$ & 2015 & Beef cattle & Gansu \\
\hline GYSF1502197 & 6 & 2015 & Yak & Gansu \\
\hline SBSF1502219 & $4 a$ & 2015 & Beef cattle & Shanxi \\
\hline XBSF1502236 & $2 b$ & 2015 & Beef cattle & Xinjiang \\
\hline GBSF1503241 & $2 a$ & 2015 & Beef cattle & Gansu \\
\hline GYSF1503270 & $1 a$ & 2015 & Yak & Gansu \\
\hline GBSF1503288 & $1 a$ & 2015 & Beef cattle & Gansu \\
\hline GBSF1505314 & $2 a$ & 2015 & Beef cattle & Gansu \\
\hline SBSF1505331 & $2 a$ & 2015 & Beef cattle & Shanxi \\
\hline GBSF1506340 & $X_{v}$ & 2015 & Beef cattle & Gansu \\
\hline GBSF1507358 & $1 a$ & 2015 & Beef cattle & Gansu \\
\hline GBSF1509369 & $2 a$ & 2015 & Beef cattle & Gansu \\
\hline GBSF1510375 & $2 a$ & 2015 & Beef cattle & Gansu \\
\hline GBSF1510390 & $2 a$ & 2015 & Beef cattle & Gansu \\
\hline QYSF1511395 & $2 a$ & 2015 & Yak & Qinghai \\
\hline GBSF1511401 & $2 a$ & 2015 & Beef cattle & Gansu \\
\hline GYSF1511409 & $2 a$ & 2015 & Yak & Gansu \\
\hline SBSF1512413 & $4 a$ & 2015 & Beef cattle & Shanxi \\
\hline GBSF1512419 & $2 b$ & 2015 & Beef cattle & Gansu \\
\hline GBSF1512425 & $2 \mathrm{a}$ & 2015 & Beef cattle & Gansu \\
\hline GBSF1512433 & $2 a$ & 2015 & Beef cattle & Gansu \\
\hline GBSF1601015 & $X_{v}$ & 2016 & Beef cattle & Gansu \\
\hline GBSF1601024 & $X_{v}$ & 2016 & Beef cattle & Gansu \\
\hline TYSF1601031 & $2 b$ & 2016 & Yak & Tibet \\
\hline GBSF1601064 & $2 a$ & 2016 & Beef cattle & Gansu \\
\hline GYSF1601073 & 6 & 2016 & Yak & Gansu \\
\hline GBSF1602082 & $2 a$ & 2016 & Beef cattle & Gansu \\
\hline QYSF1602094 & 6 & 2016 & Yak & Qinghai \\
\hline GBSF1602098 & $2 a$ & 2016 & Beef cattle & Gansu \\
\hline GBSF1602103 & $2 a$ & 2016 & Beef cattle & Gansu \\
\hline SBSF1603115 & $4 a$ & 2016 & Beef cattle & Shanxi \\
\hline SBSF1603121 & $4 a$ & 2016 & Beef cattle & Shanxi \\
\hline GBSF1603138 & $2 a$ & 2016 & Beef cattle & Gansu \\
\hline
\end{tabular}

Table 2 Strain information of S. flexneri isolates from diarrheal calves, 2014 to 2016 (Continued)

\begin{tabular}{lllll}
\hline GBSF1603149 & 2a & 2016 & Beef cattle & Gansu \\
QYSF1603158 & 6 & 2016 & Yak & Qinghai \\
SBSF1604173 & $2 a$ & 2016 & Beef cattle & Shanxi \\
SBSF1604195 & $4 a$ & 2016 & Beef cattle & Shanxi \\
GBSF1605203 & Xv & 2016 & Beef cattle & Gansu \\
GBSF1608241 & $2 a$ & 2016 & Beef cattle & Gansu \\
GYSF1610256 & $2 a$ & 2016 & Yak & Gansu \\
GYSF1610266 & 6 & 2016 & Yak & Gansu \\
GBSF1610275 & $1 a$ & 2016 & Beef cattle & Gansu \\
GBSF1611283 & $1 a$ & 2016 & Beef cattle & Gansu \\
GBSF1611290 & 2a & 2016 & Beef cattle & Gansu \\
\hline
\end{tabular}

Among all isolates, the majority of S. flexneri 2a (26/54, 48.15\%) isolates were classified into 11 PFGE patterns (4 $\mathrm{CT}$ and $7 \mathrm{ST}$ ). These PFGE patterns were closely related to each other, except the Tibet (TYSF1412001) and Qinghai (QYSF1511395) isolates, suggesting the strains isolated from different geographical locations exhibit diverse PFGE patterns and a capricious genetic diversity.

\section{Discussion}

ARGs are widespread and cause problems when present in pathogens [26]. Over the past decade, MDR Shigella has been reported in many countries [27]. However, only a few studies have described the prevalence of Shigella in animals worldwide. In the present study, we investigated the epidemiology of $S$. flexneri in cows in northwest

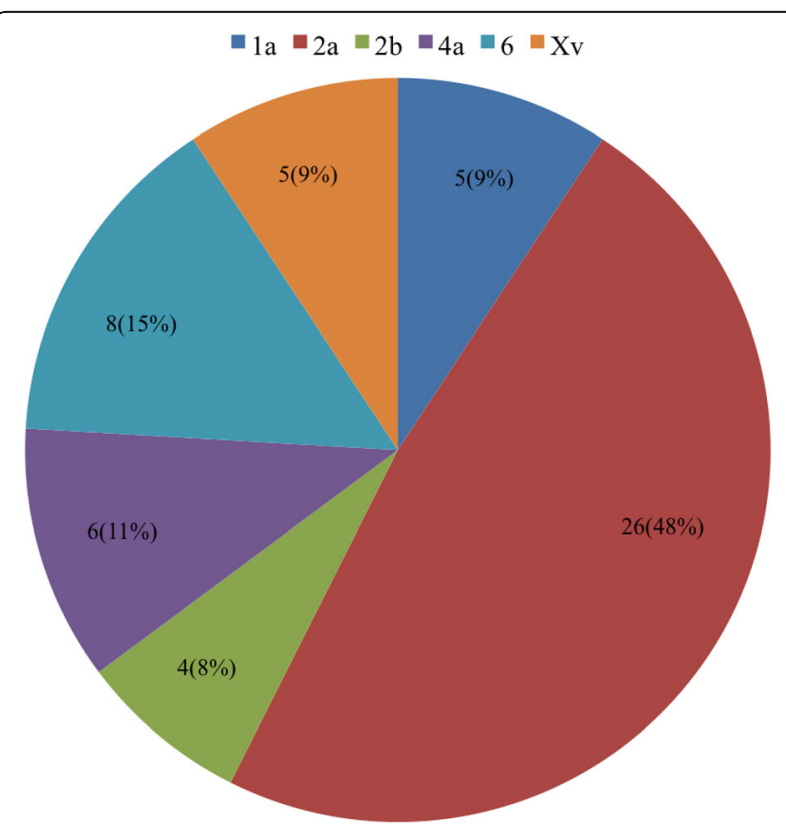

Fig. 1 S. flexneri serotypes collected from 2014 to 2016 


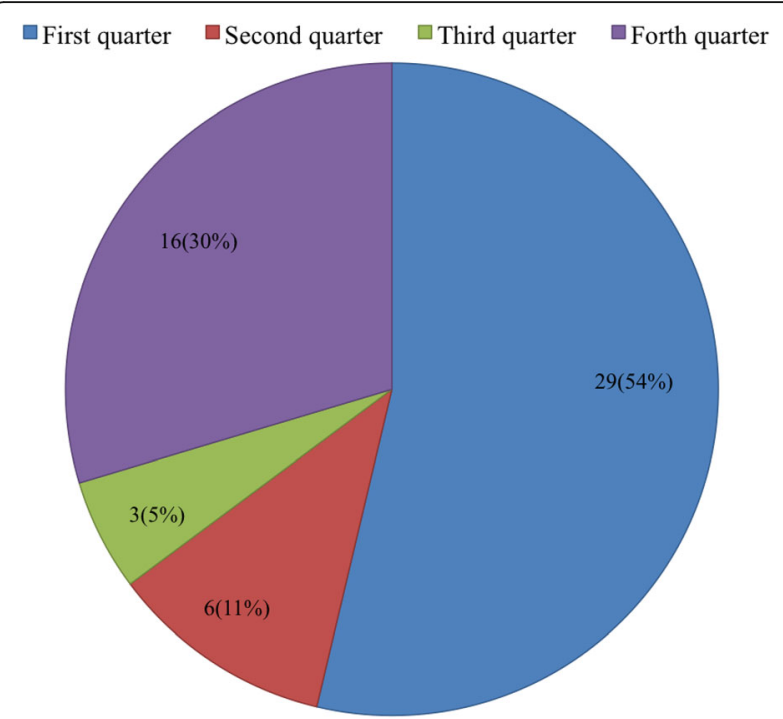

Fig. 2 Number of S. flexneri isolated from different quarters
China. During a 2-year survey, $54 \mathrm{~S}$. flexneri isolates were obtained. Unfortunately, 16S rRNA gene sequence analysis does not effectively distinguish between closely related strains in a superfamily, such as Shigella and E. coli [28], and conventional biochemical and serological techniques are also insufficient. Therefore, PFGE was utilized to analyze the molecular characteristics of these isolates, to determine the relatedness among isolates and to study the molecular epidemiology in specific geographical regions. The clustering results allowed us to analyze the epidemiological trends of $S$. flexneri. Characterization of these isolates will be helpful for clinical diagnosis, treatment, prevention and the control of shigellosis [15].

Antimicrobial resistance has emerged as a serious problem [29], particularly for conventional, older-generation antibiotics such as P, AMP, TE, and E. According to the results of our antimicrobial susceptibility tests, cephalosporin and fluoroquinolone resistance rates in our isolates were higher than those in human isolates $[19,26]$. Notably, the predominant $S$. flexneri 2a isolates were all resistant to cephalosporins, fluoroquinolones and multiple antibiotics. Two isolates (GBSF1505314 and GBSF1602098) were also resistant to ciprofloxacin, which is the first-line antibiotic

Table 3 Statistical analysis of the results of antimicrobial susceptibility to 23 antibiotics for 54 S. flexneri

\begin{tabular}{|c|c|c|c|c|c|c|}
\hline \multirow[t]{2}{*}{ Antibiotic } & \multicolumn{6}{|c|}{ Antimicrobial resistance rate No. (\%) } \\
\hline & Total $(n=54)$ & Gansu $(n=37)$ & Shanxi $(n=8)$ & Xinjiang $(n=2)$ & Qinghai $(n=5)$ & Tibet $(n=2)$ \\
\hline Penicillin G (P) & $54(100 \%)$ & $37(100 \%)$ & $8(100 \%)$ & $2(100 \%)$ & $5(100 \%)$ & $2(100 \%)$ \\
\hline Ampicillin (AMP) & $51(94.44 \%)$ & $37(100 \%)$ & $8(100 \%)$ & $2(100 \%)$ & $3(60 \%)$ & $1(50 \%)$ \\
\hline Amoxycillin/Clavulanic acid (AMC) & $5(9.62 \%)$ & $3(8.11 \%)$ & $1(12.5 \%)$ & $1(50 \%)$ & 0 & 0 \\
\hline Cephalothin (KF) & $29(53.70 \%)$ & $19(51.35 \%)$ & $5(62.5 \%)$ & $2(100 \%)$ & $2(40 \%)$ & $1(50 \%)$ \\
\hline Cephazolin (KZ) & $34(62.96 \%)$ & $21(56.76 \%)$ & $7(87.5 \%)$ & $2(100 \%)$ & $3(60 \%)$ & $1(50 \%)$ \\
\hline Cefamandole (MA) & $16(29.63 \%)$ & $12(32.43 \%)$ & $2(25 \%)$ & $1(50 \%)$ & $1(20 \%)$ & 0 \\
\hline Cefoxitin (FOX) & $3(5.56 \%)$ & $2(5.41 \%)$ & $1(12.5 \%)$ & 0 & 0 & 0 \\
\hline Ceftriaxone (CRO) & $12(22.22 \%)$ & $9(24.32 \%)$ & $2(25 \%)$ & $1(50 \%)$ & 0 & 0 \\
\hline Cefotaxime (CTX) & $14(25.93 \%)$ & $10(27.03 \%)$ & $2(25 \%)$ & $1(50 \%)$ & $1(20 \%)$ & 0 \\
\hline Cefoperazone (CFP) & $6(11.11 \%)$ & $6(16.22 \%)$ & 0 & 0 & 0 & 0 \\
\hline Cefepime (FEP) & 0 & 0 & 0 & 0 & 0 & 0 \\
\hline Meropenem (MEM) & 0 & 0 & 0 & 0 & 0 & 0 \\
\hline Imipenem (IPM) & 0 & 0 & 0 & 0 & 0 & 0 \\
\hline Norfloxacin (NOR) & $16(29.63 \%)$ & $12(32.43 \%)$ & $3(37.5 \%)$ & $1(50 \%)$ & 0 & 0 \\
\hline Enrofloxacin (ENR) & $13(24.07 \%)$ & $11(29.73 \%)$ & $2(25 \%)$ & 0 & 0 & 0 \\
\hline Levofloxacin (LEV) & $14(25.93 \%)$ & $11(29.73 \%)$ & $2(25 \%)$ & $1(50 \%)$ & 0 & 0 \\
\hline Ciprofloxacin (CIP) & $2(3.70 \%)$ & $2(5.41 \%)$ & 0 & 0 & 0 & 0 \\
\hline Erythromycin (E) & $46(85.19 \%)$ & 35 (94.59\%) & $6(75 \%)$ & $2(100 \%)$ & $3(60 \%)$ & 0 \\
\hline Tetracycline (TE) & $49(90.74 \%)$ & 35 (94.59\%) & $8(100 \%)$ & $2(100 \%)$ & $3(60 \%)$ & $1(50 \%)$ \\
\hline Chloramphenicol (C) & $17(31.48 \%)$ & $10(27.03 \%)$ & $6(75 \%)$ & $1(50 \%)$ & 0 & 0 \\
\hline Streptomycin (S) & $38(70.37 \%)$ & $30(81.08 \%)$ & $4(50 \%)$ & $2(100 \%)$ & $2(40 \%)$ & 0 \\
\hline Gentamicin (CN) & $29(53.70 \%)$ & $23(62.16 \%)$ & $4(50 \%)$ & $2(100 \%)$ & 0 & 0 \\
\hline Amikacin (AK) & $3(5.56 \%)$ & $3(8.11 \%)$ & 0 & 0 & 0 & 0 \\
\hline
\end{tabular}




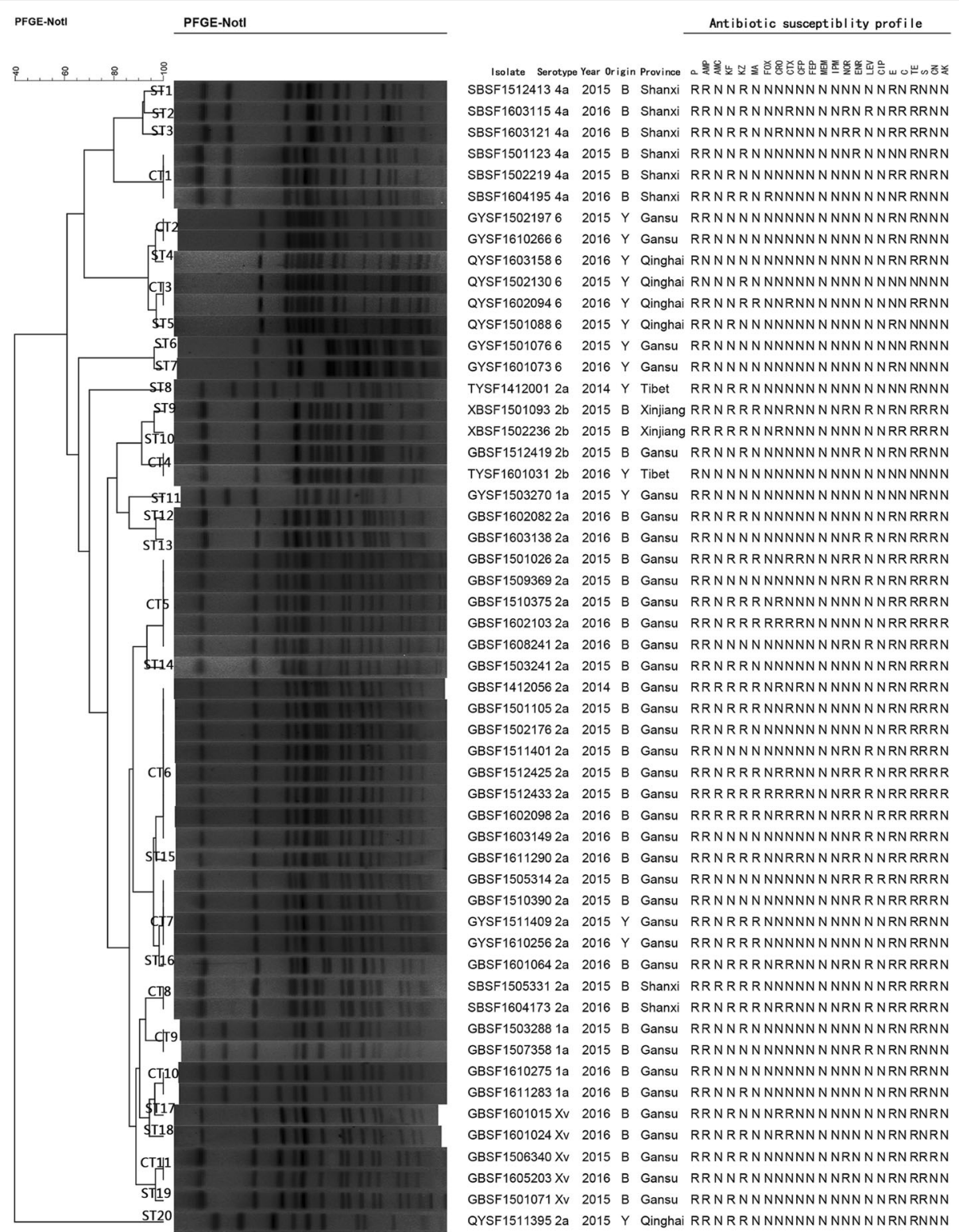

Fig. 3 PFGE dendrogram and antibiotic susceptibility profile of 54 Notl-digested S. flexneri. $B=$ Beef cattle; $Y=$ Yak. $R=$ Resistance; $N=$ Sensitive and Intermediary

treatment for shigellosis. The universal emergence of resistant and MDR strains in animals may be attributable to the unrestricted and excessive use of antibiotics in veterinary clinics. The widespread presence of MDR strains has reduced the selectivity of clinical medications to treat shigellosis [30]. Notably, our PFGE dendrogram showed various genetic patterns for $S$. flexneri, and there were diverse resistance profiles associated with each pattern. Based on these results, S. flexneri has the ability to adapt to the selective pressures of different antibiotics.

The high levels of resistance of S. flexneri 2a to cephalosporin/fluorquinolones, which are the most effective treatments for severe gastrointestinal infections caused by pathogenic bacteria, prompted us to study potential molecular resistance mechanisms. The emergence of ESBL-producing Shigella spp. has been observed in many countries [31]. In the current study, only 3 ARG genotypes (bla $a_{O X A-1}, b l a_{T E M-1}$ and $\left.b l a_{C T X-M-14}\right)$ were detected. Among them, the bla $a_{T E M-1}$ gene was detected in all 19 cephalosporin-resistant isolates. In total, 174 bla $a_{T E M}$ variants resistant to penicillin and other $B$-lactamase antibiotics have been recorded. TEM-1 confers resistance to ampicillin and cephalothin [32]. bla OXA- $^{-}$ type ARGs are class D $\beta$-lactamases, which were named for their ability to hydrolyze oxacillin [32]. Initially, bla $a_{O X A}$-beta-lactamases were reported in P. aeruginosa, 
Table 4 Statistical analysis of the cephalosporin and/or fluoroquinolone susceptibility for 26 S. flexneri 2a

\begin{tabular}{|c|c|c|c|c|c|}
\hline \multirow{2}{*}{$\begin{array}{l}\text { Cephalosporin and/or Fluorquinolones } \\
\text { resistance spectrum }\end{array}$} & \multicolumn{5}{|c|}{ Cephalosporin and/or Fluorquinolones resistance rate No. (\%) } \\
\hline & Total $(n=26)$ & Gansu $\left(n=22^{a}\right)$ & Shanxi $(n=2)$ & Qinghai $\left(n=1^{a}\right)$ & Tibet $\left(n=1^{\mathrm{a}}\right)$ \\
\hline $\mathrm{KF} / \mathrm{KZ}$ & $5(19.23 \%)$ & $3(13.64 \%)$ & 0 & $1^{\mathrm{a}}(100 \%)$ & $1^{\mathrm{a}}(100 \%)$ \\
\hline $\mathrm{KF} / \mathrm{KZ} / \mathrm{MA}$ & $3(11.54 \%)$ & $2^{\mathrm{a}}(9.09 \%)$ & $1(50 \%)$ & 0 & 0 \\
\hline $\mathrm{KF} / \mathrm{KZ} / \mathrm{MA} / \mathrm{CRO}$ & $1(3.85 \%)$ & $1(4.55 \%)$ & 0 & 0 & 0 \\
\hline $\mathrm{KF} / \mathrm{KZ} / \mathrm{MA} / \mathrm{CTX}$ & $1(3.85 \%)$ & $1(4.55 \%)$ & 0 & 0 & 0 \\
\hline $\mathrm{KF} / \mathrm{KZ} / \mathrm{MA} / \mathrm{CRO} / \mathrm{CFP}$ & $1(3.85 \%)$ & $1(4.55 \%)$ & 0 & 0 & 0 \\
\hline $\mathrm{KF} / \mathrm{KZ} / \mathrm{MA} / \mathrm{FOX} / \mathrm{CRO} / \mathrm{CTX} / \mathrm{CFP}$ & $1(3.85 \%)$ & $1(4.55 \%)$ & 0 & 0 & 0 \\
\hline NOR/LEV & $3(11.54 \%)$ & $3(13.64 \%)$ & 0 & 0 & 0 \\
\hline ENR/LEV & $3(11.54 \%)$ & $3(13.64 \%)$ & 0 & 0 & 0 \\
\hline NOR/ENR/LEV/CIP & $1(3.85 \%)$ & $1(4.55 \%)$ & 0 & 0 & 0 \\
\hline $\mathrm{KF} / \mathrm{KZ} / \mathrm{MA} / \mathrm{CRO} / \mathrm{CTX} / \mathrm{NOR} / \mathrm{LEV}$ & $2(7.69 \%)$ & $1(4.55 \%)$ & $1(50 \%)$ & 0 & 0 \\
\hline KF/KZ/MA/CRO/CTX/NOR/ENR/LEV & $1(3.85 \%)$ & $1(4.55 \%)$ & 0 & 0 & 0 \\
\hline KF/KZ/MA/CTX/CFP/CIP/NOR/ENR & $2(7.69 \%)$ & $2(9.09 \%)$ & 0 & 0 & 0 \\
\hline KF/KZ/MA/CRO/CTX/CFP/NOR/ENR/CIP & $1(3.85 \%)$ & $1(4.55 \%)$ & 0 & 0 & 0 \\
\hline KF/KZ/MA/FOX/CRO/CTX/CFP/NOR/ENR/LEV & $1(3.85 \%)$ & $1(4.55 \%)$ & 0 & 0 & 0 \\
\hline
\end{tabular}

a yak origin $S$. flexneri $2 a$ isolate

although now the bla $a_{O X A}$ gene has been detected in plasmids and integrons in many Gram-negative organisms $[32,33]$. According to some studies, the probable host preference for $b l a_{O X A}$-type $\beta$-lactamase is $S$. flexneri [34]. In the present study, 15/19 (78.95\%) isolates harbored bla $a_{O X A^{-}}$type genes, and sequencing results indicated that all the bla $a_{O X A}$ genes were bla $a_{O X A-1}$. Additionally, bla $a_{C T X-M}$ has become one of the most prevalent extended-spectrum- $\beta$-lactamases (ESBLs) [35]. This gene was widely harbored by S. flexneri $2 \mathrm{a}$ isolated

Table 5 Antimicrobial spectrum and ARGs analysis of S. flexneri 2a with resistance to cephalosporin

\begin{tabular}{|c|c|c|c|c|}
\hline \multirow[t]{2}{*}{ Strain name } & \multirow[t]{2}{*}{ Antimicrobial spectrum } & \multicolumn{3}{|c|}{ ARGs in plasmid } \\
\hline & & TEM & OXA & CTX-M-9 \\
\hline TYSF1412001 & $\mathrm{KF} / \mathrm{KZ}$ & TEM-1 & $O X A-1$ & -- \\
\hline QYSF1511395 & $\mathrm{KF} / \mathrm{KZ}$ & TEM-1 & -- & - \\
\hline GBSF1503241 & $\mathrm{KF} / \mathrm{KZ}$ & TEM-1 & $O X A-1$ & CTX-M-14 \\
\hline GBSF1502176 & $\mathrm{KF} / \mathrm{KZ}$ & TEM-1 & $O X A-1$ & CTX-M-14 \\
\hline GBSF1602082 & $\mathrm{KF} / \mathrm{KZ}$ & TEM-1 & -- & CTX-M-14 \\
\hline SBSF1505331 & KF/KZ/MA & TEM-1 & $O X A-1$ & CTX-M-14 \\
\hline GYSF1511409 & $\mathrm{KF} / \mathrm{KZ} / \mathrm{MA}$ & TEM-1 & -- & - \\
\hline GYSF1610256 & KF/KZ/MA & TEM-1 & $O X A-1$ & - \\
\hline GBSF1510375 & $\mathrm{KF} / \mathrm{KZ} / \mathrm{MA} / \mathrm{CRO}$ & TEM-1 & $O X A-1$ & CTX-M-14 \\
\hline GBSF1501105 & $\mathrm{KF} / \mathrm{KZ} / \mathrm{MA} / \mathrm{CTX}$ & TEM-1 & $O X A-1$ & CTX-M-14 \\
\hline GBSF1412056 & $\mathrm{KF} / \mathrm{KZ} / \mathrm{MA} / \mathrm{CRO} / \mathrm{CFP}$ & TEM-1 & $O X A-1$ & CTX-M-14 \\
\hline GBSF1602103 & KF/KZ/MA/FOX/CRO/CTX/CFP & TEM-1 & $O X A-1$ & CTX-M-14 \\
\hline GBSF1601064 & KF/KZ/MA/CRO/CTX/NOR/LEV & TEM-1 & - & CTX-M-14 \\
\hline SBSF1604173 & $\mathrm{KF} / \mathrm{KZ} / \mathrm{MA} / \mathrm{CRO} / \mathrm{CTX} / \mathrm{NOR} / \mathrm{LEV}$ & TEM-1 & $O X A-1$ & CTX-M-14 \\
\hline GBSF1611290 & KF/KZ/MA/CTX/CFP/NOR/ENR & TEM-1 & $O X A-1$ & CTX-M-14 \\
\hline GBSF1501026 & KF/KZ/MA/CTX/CFP/NOR/ENR & TEM-1 & $O X A-1$ & CTX-M-14 \\
\hline GBSF1512425 & KF/KZ/MA/CRO/CTX/NOR/ENR/LEV & TEM-1 & $O X A-1$ & - \\
\hline GBSF1602098 & KF/KZ/MA/CRO/CTX/CFP/NOR/ENR/CIP & TEM-1 & $O X A-1$ & CTX-M-14 \\
\hline GBSF1512433 & KF/KZ/MA/FOX/CRO/CTX/CFP/NOR/ENR/LEV & TEM-1 & $O X A-1$ & CTX-M-14 \\
\hline
\end{tabular}


Table 6 Antimicrobial spectrum and amino acid types in QRDR and PMQRs genes analysis of S. flexneri 2a with resistance to fluoroquinolones

\begin{tabular}{|c|c|c|c|c|c|c|c|}
\hline \multirow[t]{3}{*}{ Strain name } & \multirow[t]{3}{*}{ Antimicrobial spectrum } & \multicolumn{3}{|l|}{ QRDR } & \multicolumn{3}{|c|}{ ARGs in plasmid } \\
\hline & & \multicolumn{2}{|l|}{ gyrA } & \multirow{2}{*}{$\begin{array}{l}\text { parC } \\
80\end{array}$} & \multirow[t]{2}{*}{$a a c\left(6^{\prime}\right)-1 b-c r$} & \multirow[t]{2}{*}{ gnrs } & \multirow[t]{2}{*}{ qepA } \\
\hline & & 83 & 87 & & & & \\
\hline GBSF1509369 & NOR/LEV & S83 L & D87N & 5801 & + & - & - \\
\hline GBSF1511401 & NOR/LEV & $\mathrm{S} 83 \mathrm{~L}$ & D87N & S801 & + & - & - \\
\hline GBSF1608241 & NOR/LEV & $\mathrm{S} 83 \mathrm{~L}$ & D87N & S801 & + & - & - \\
\hline GBSF1510390 & ENR/LEV & S83 L & D87D & S801 & + & + & - \\
\hline GBSF1603138 & ENR/LEV & $\mathrm{S} 83 \mathrm{~L}$ & D87N & S801 & + & - & - \\
\hline GBSF1603149 & ENR/LEV & S83 L & D87N & 5801 & + & - & - \\
\hline GBSF1505314 & NOR/ENR/LEV/CIP & $\mathrm{S} 83 \mathrm{~L}$ & D87Y & S801 & + & + & - \\
\hline GBSF1601064 & KF/KZ/MA/CRO/CTX/NOR/LEV & $S 83 \mathrm{~L}$ & D87N & S801 & + & - & - \\
\hline SBSF1604173 & KF/KZ/MA/CRO/CTX/NOR/LEV & S83 L & D87N & S801 & + & - & - \\
\hline GBSF1611290 & KF/KZ/MA/CTX/CFP/NOR/ENR & S83 L & D87N & S801 & + & - & - \\
\hline GBSF1501026 & KF/KZ/MA/CTX/CFP/NOR/ENR & S83 L & D87N & S801 & + & + & - \\
\hline GBSF1512425 & KF/KZ/MA/CRO/CTX/NOR/ENR/LEV & S83 L & $\mathrm{D} 87 \mathrm{~N}$ & S801 & + & + & - \\
\hline GBSF1602098 & KF/KZ/MA/CRO/CTX/CFP/NOR/ENR/CIP & S83 L & D87Y & S801 & + & - & + \\
\hline GBSF1512433 & KF/KZ/MA/FOX/CRO/CTX/CFP/NOR/ENR/LEV & S83 L & D87N & S80I & + & + & - \\
\hline
\end{tabular}

+: Presence corresponding genes

-: Absence corresponding genes

from beef cattle. Interestingly, all S. flexneri 2a isolated from yaks were negative for $b a_{C T X-M}$ type ARGs.

Fluoroquinolones are highly effective for the treatment of shigellosis worldwide [36]. The primary mechanism of quinolone resistance involves the accumulation of sequential mutations in QRDRs that encode DNA gyrase and topoisomerase IV [37]. The most prevalent mutations in Shigella spp. are the point mutations in gyrA codons 83, 87 and 211, and parC codon 80 [38, 39]. Novel mutations in QRDRs are also being discovered [39]. In the present study, three mutations in gyrA codon $83(\mathrm{~S} \rightarrow \mathrm{L})$ and/or $87(\mathrm{D} \rightarrow \mathrm{N}$ or $\mathrm{Y}$ ) and parC codon 80 $(\mathrm{S} \rightarrow \mathrm{I})$ were detected in each fluoroquinolone-resistant isolate. All substitutions are responsible for reduced affinity. In addition, the amino acid diversity at the same position may lead to different levels of quinolone resistance $[40,41]$. GyrA D87Y mutations were detected in only two ciprofloxacin-resistant isolates. However, the role of this mutation in ciprofloxacin resistance is unclear and requires further investigation.

Over the past few years, PMQR determinants have been deemed the most common ARGs in Enterobacteriaceae worldwide [42]. PMQR determinants mediate only low-level quinolone resistance. However, these resistance genes are usually associated with mobile or transposable elements that allow for dissemination among Enterobacteriaceae. In addition, the presence of PMQR genes may facilitate the selection of QRDR mutations that result in higher levels of quinolone resistance [37, 43, 44]. The $a a c\left(6^{\prime}\right)-I b-c r$ gene encodes an acetyltransferase that is known to reduce quinolone activity. In the present study, all 14 isolates resistant to fluoroquinolones were positive for $a a c\left(6^{\prime}\right)-I b-c r$, indicating the $a a c\left(6^{\prime}\right)-I b-c r$ gene is widespread in S. flexneri 2a. Compared with the $a a c\left(6^{\prime}\right)-I b-c r$ gene, the transmembrane segment efflux pump qepA gene was scarcely detected in Shigella, and we found only one ciprofloxacin-resistant isolate that was qepA-positive. The qnr family (which includes the first PMQR genes) contains a variety of subtypes, including $q n r A, q n r B$, qnrC, qnrD and qnrS and several qnr family genes that have been reported in Shigella $[39,45]$. The Qnr proteins protect DNA gyrase against quinolones and facilitate the selection of QRDR mutations that improve resistance to these antimicrobials.

\section{Conclusion}

In conclusion, cephalosporin and/or fluoroquinolone resistance in Shigella has been widely reported. To increase our understanding of Shigella in cattle, we investigated Shigella in calves with diarrhea and analyzed the genetic relatedness, antimicrobial susceptibility, QRDR mutations, and prevalence of PMQR and ß-lactamase in S. flexneri 2a isolates from five provinces in northwest China. However, this study also had limitations, including the lack of a systematic surveillance system to prospectively or retrospectively detect and analyze shigellosis in veterinary clinics. Furthermore, we are unable to effectively monitor and control antibiotic abuse and the resulting spread of ARGs. Therefore, it is essential to continually monitor rates of shigellosis and the development of resistance patterns. 


\section{Acknowledgements}

The authors thank all the farms for providing the samples in this study.

\section{Funding}

This work was supported by funds from the National Natural Science Foundation of China $(31,272,603,31,101,836)$.

\section{Availability of data and materials}

The data supporting the findings of this study are contained within the manuscript.

\section{Authors' contributions}

Conceived and designed the experiments: JYZ and ZZ. Performed the experiments: ZZ and MZC. Analyzed the data: ZZ, BL, and XZZ. Contributed reagents/materials/analysis tools: MZC and FSC. Wrote the paper: ZZ. All authors read and approved the final manuscript.

\section{Ethics approval and consent to participate}

Permission to work in specific locations, information regarding the number of samples harvested, and an associated permit number for calves were not required, and no endangered or protected species were involved or harmed during this study.

\section{Consent for publication}

All authors agreed on the publication of the paper.

\section{Competing interests}

The authors declare that they have no competing interests.

\section{Publisher's Note}

Springer Nature remains neutral with regard to jurisdictional claims in published maps and institutional affiliations.

Received: 27 June 2017 Accepted: 30 August 2017

Published online: 06 September 2017

\section{References}

1. Nandre R, Matsuda K, Lee JH. Efficacy for a new live attenuated Salmonella Enteritidis vaccine candidate to reduce internal egg contamination. Zoonoses Public Health. 2014;61:55-63.

2. Nandre RM, Ruan X, Duan Q, Sack DA, Zhang W. Antibodies derived from an enterotoxigenic Escherichia coli (ETEC) adhesin tip MEFA (multiepitope fusion antigen) against adherence of nine ETEC adhesins: CFA/I, CS1, CS2, CS3, CS4, CS5, CS6, CS21 and EtpA. Vaccine. 2016;34:3620-5.

3. Rausch D, Ruan X, Nandre R, Duan Q, Hashish E, Casey TA, et al. Antibodies derived from a toxoid MEFA (multiepitope fusion antigen) show neutralizing activities against heat-labile toxin (LT), heat-stable toxins (STa, $\mathrm{STb})$, and Shiga toxin 2e (Stx2e) of porcine enterotoxigenic Escherichia coli (ETEC). Vet Microbiol. 2017;202:79-89.

4. Pupo GM, Lan R, Reeves PR. Multiple independent origins of Shigella clones of Escherichia coli and convergent evolution of many of their characteristics. Proc Natl Acad Sci U S A. 2000;97:10567-72.

5. Livio S, Strockbine NA, Panchalingam S, Tennant SM, Barry EM, Marohn ME, et al. Shigella isolates from the global enteric multicenter study inform vaccine development. Clin Infect Dis. 2014;59:933-41.

6. Linton DS. "War dysentery" and the limitations of German military hygiene during world war I. Bull Hist Med. 2010;84:607-39.

7. Baker KS, Mather AE, McGregor H, Coupland P, Langridge GC, Day M, et al. The extant world war 1 dysentery bacillus NCTC1: a genomic analysis. Lancet. 2014;384:1691-7.

8. Sun $Q$, Lan $R$, Wang J, Xia S, Wang $Y$, Wang $Y$, et al. Identification and characterization of a novel Shigella flexneri serotype $Y v$ in China. PLoS One. 2013:8:e70238.

9. Qiu S, Xu X, Yang C, Wang J, Liang B, Li P, et al. Shift in serotype distribution of Shigella species in China, 2003-2013. Clin Microbiol Infect. 2015:21:252. e5-8

10. Priamukhina NS, Kilesso VA, Tikhomirov ED. Animal carriers of Shigella and their possible epidemiological importance. Zh Mikrobiol Epidemiol Immunobiol. 1984;11:20-4.
11. Fang $H$, Wang H, Cai L, Yu Y. Prevalence of antibiotic resistance genes and bacterial pathogens in long-term manured greenhouse soils as revealed by metagenomic survey. Environ Sci Technol. 2015;49:1095-104.

12. Wang Q, Qian L, Jiang S, Cai C, Ma D, Gao P, et al. Safety evaluation of neo transgenic pigs by studying changes in gut microbiota using highthroughput sequencing technology. PLoS One. 2016;11:e0150937.

13. Mohammed AN, Abdel-Latef GK, Abdel-Azeem NM, El-Dakhly KM. Ecological study on antimicrobial-resistant zoonotic bacteria transmitted by flies in cattle farms. Parasitol Res. 2016;115:3889-96.

14. Qu F, Bao C, Chen S, Cui E, Guo T, Wang H, et al. Genotypes and antimicrobial profiles of Shigella sonnei isolates from diarrheal patients circulating in Beijing between 2002 and 2007. Diagn Microbiol Infect Dis. 2012;74:166-70.

15. Li S, Sun Q, Wei X, Klena JD, Wang J, Liu Y, et al. Genetic characterization of Shigella flexneri isolates in Guizhou Province, China. PLoS One. 2015;10: e0116708.

16. Cui X, Wang J, Yang C, Liang B, Ma Q, Yi S, et al. Prevalence and antimicrobial resistance of Shigella flexneri serotype 2 variant in China. Front Microbiol. 2015;6:435

17. Sun Q, Lan R, Wang Y, Zhao A, Zhang S, Wang J, et al. Development of a multiplex PCR assay targeting O-antigen modification genes for molecular serotyping of Shigella flexneri. J Clin Microbiol. 2011;49:3766-70.

18. Clinical Laboratory Standards Institute. Performance standards for antimicrobial disk susceptibility testing; twenty-second informational supplement. Wayne: Clinical and Laboratory Standards Institute; 2013. p. m100-s23.

19. Cui $X$, Yang C, Wang J, Liang B, Yi S, Li H, et al. Antimicrobial resistance of Shigella flexneri serotype 1b isolates in China. PLoS One. 2015;10:e0129009.

20. Zong Z, Partridge SR, Thomas L, Iredell JR. Dominance of blaCTX-M within an Australian extended-spectrum beta-lactamase gene pool. Antimicrob Agents Chemother. 2008;52:4198-202.

21. Liu J, Zeng T, Su G, Lin LY, Zhao Y, Yang WQ, et al. The dissemination mode of drug-resistant genes in Enterobacter Cloacae. Indian J Med Microbiol. 2015;33:87-92.

22. Colobatiu L, Tabaran A, Flonta M, Oniga O, Mirel S, Mihaiu M. First description of plasmid-mediated quinolone resistance determinants and $\beta$-lactamase encoding genes in non-typhoidal Salmonella isolated from humans, one companion animal and food in Romania. Gut Pathog. 2015;7:16.

23. Hu LF, Li JB, Ye Y, Li X. Mutations in the GyrA subunit of DNA gyrase and the ParC subunit of topoisomerase IV in clinical strains of fluoroquinoloneresistant Shigella in Anhui, China. J Microbiol. 2007;45:168-70.

24. Komp Lindgren PD, Karlsson A, Hughes D. Mutation rate and evolution of fluoroquinolone resistance in Escherichia coli isolates from patients with urinary tract infections. Antimicrob Agents Chemother. 2003;47:3222-32.

25. Dutta S, Jain P, Nandy S, Matsushita S, Yoshida S. Molecular characterization of serologically atypical provisional serovars of Shigella isolates from Kolkata, India. J Med Microbiol. 2014:63:1696-703.

26. Pal C, Bengtsson-Palme J, Kristiansson E, Larsson DGJ. The structure and diversity of human, animal and environmental resistomes. Microbiome. 2016:4:54.

27. Ahmed AM, Furuta K, Shimomura K, Kasama Y, Shimamoto T. Genetic characterization of multidrug resistance in Shigella spp. from japan. J Med Microbiol. 2006:55:1685-91.

28. Demarta A, De Respinis S, Dolina M, Peduzzi R. Molecular typing of Yersinia frederiksenii strains by means of $16 \mathrm{~s}$ rDNA and gyrB genes sequence analyses. FEMS Microbiol Lett. 2004:238:423-8.

29. Ud-Din Al, Wahid SU, Latif HA, Shahnaij M, Akter M, Azmi IJ, et al. Changing trends in the prevalence of Shigella species: emergence of multi-drug resistant Shigella sonnei biotype $\mathrm{g}$ in Bangladesh. PLoS One. 2013;8:e82601.

30. Wright DJ, Drasar BS. Dysentery in world war 1: Shigella a century on. Lancet. 2014;384:1651-3.

31. Tajbakhsh M, García Migura LM, Rahbar M, Svendsen CA, Mohammadzadeh M, Zali MR, et al. Antimicrobial-resistant Shigella infections from Iran: an overlooked problem? J Antimicrob Chemother. 2012;67:1128-33.

32. Pfeifer $Y$, Cullik $A$, Witte $W$. Resistance to cephalosporins and carbapenems in gram-negative bacterial pathogens. Int J Med Microbiol. 2010;300:371-9.

33. Sugumar M, Kumar KM, Manoharan A, Anbarasu A, Ramaiah S. Detection of OXA-1 $\beta$-lactamase gene of Klebsiella pneumoniae from blood stream infections (BSI) by conventional PCR and in-silico analysis to understand the mechanism of OXA mediated resistance. PLoS One. 2014;9:e91800.

34. Navia MM, Capitano L, Ruiz J, Vargas M, Urassa H, Schellemberg D, et al. Typing and characterization of mechanisms of resistance of Shigella spp. isolated from feces of children under 5 years of age from Ifakara, Tanzania. $J$ Clin Microbiol. 1999;37:3113-7. 
35. Robin F, Beyrouthy R, Bonacorsi S, Aissa N, Bret L, Brieu N, et al. Inventory of extended-spectrum-beta-lactamase-producing enterobacteriaceae in France as assessed by a multicenter study. Antimicrob Agents Chemother. 2017;61

36. Taneja N, Kumar A, Appannanavar S, Verma G, Sharma M. Plasmid-mediated quinolone resistance in Shigella isolates over a decade in India. J Glob Antimicrob Resist. 2014;2:59-60.

37. Yang H, Duan $G$, Zhu J, Zhang W, Xi Y, Fan Q. Prevalence and characterisation of plasmid-mediated quinolone resistance and mutations in the gyrase and topoisomerase IV genes among Shigella isolates from Henan, China, between 2001 and 2008. Int J Antimicrob Agents. 2013;42:173-7.

38. Kamonporn P, Ladaporn B, Sivhour C, Wilawan O, Sirigade R, Panida N, et al. Multidrug-resistant infections in patients with diarrhea, Cambodia, 20142015. Emerg Infect Dis. 2016;22:1640-3.

39. Gu B, Qin TT, Fan WT, Bi RR, Chen Y, Li Y, et al. Novel mutations in gyrA and parC among Shigella sonnei strains from Jiangsu Province of China, 20022011. Int J Infect Dis. 2017;59:44-9.

40. Ruiz J. Mechanisms of resistance to quinolones: target alterations, decreased accumulation and DNA gyrase protection. J Antimicrob Chemother. 2003; 51:1109-17.

41. Tamanna RJ, Ramana J. Structural insights into the fluoroquinolone resistance mechanism of Shigella flexneri DNA gyrase and topoisomerase IV. Microb Drug Resist. 2016;22:404-11.

42. Pu XY, Pan JC, Gu YM, Zheng W, Li J, Yu H. Complete sequences and characterization of two novel plasmids carrying aac $\left(6^{\prime}\right)-1 \mathrm{~b}$-cr and anrS gene in Shigella flexneri. Microb Drug Resist. 2016;22:115-22.

43. Folster JP, Pecic G, Bowen A, Rickert R, Carattoli A, Whichard JM. Decreased susceptibility to ciprofloxacin among Shigella isolates in the United States, 2006 to 2009. Antimicrob Agents Chemother. 2011;55:1758-60.

44. Rodríguez-Martínez JM, Machuca J, Cano ME, Calvo J, Martínez-Martínez L, Pascual A. Plasmid-mediated quinolone resistance: two decades on. Drug Resist Updat. 2016;29:13-29.

45. Zaidi MB, Estrada-García T, Campos FD, Chim R, Arjona F, Leon M, et al. Incidence, clinical presentation, and antimicrobial resistance trends in Salmonella and Shigella infections from children in Yucatan, Mexico. Front Microbiol. 2013;4:288.

\section{Submit your next manuscript to BioMed Central and we will help you at every step:}

- We accept pre-submission inquiries

- Our selector tool helps you to find the most relevant journal

- We provide round the clock customer support

- Convenient online submission

- Thorough peer review

- Inclusion in PubMed and all major indexing services

- Maximum visibility for your research

Submit your manuscript at www.biomedcentral.com/submit

) Biomed Central 